\title{
TEKNOEKONOMI ALAT PEMURNI AIR MENGGUNAKAN ENERGI LISTRIK TERBUANG DI PLTMH GUNUNG SAWUR 1 LUMAJANG
}

Techno-economy of Water Purifier Using Wasted Electric Energy in PLTMH Gunung Sawur 1 Lumajang

\author{
Dedy Eko Rahmanto ${ }^{1) *}$, Valency Femintasari ${ }^{1)}$ \\ ${ }^{1)}$ Program Studi Teknik Energi Terbarukan, Politeknik Negeri Jember \\ Jalan Mastrip Kotak Pos 164 Jember \\ *Korespondensi Penulis: dedy_eko@polije.ac.id
}

\begin{abstract}
Water purification is carried out to separate water from minerals in it. One process of water purification is distillation. Water destilator require heat that can be obtained from electricity. The Gunung Sawur 1 Microhydro produces electricity for the surrounding society. But, not all electricity produced by microhydro was used. Excess of electricity from microhydro discharged into dummy load for balancing. The potency of wasted electrical energy can be used for water distillation. The purpose of this research were to make a plan about water purification using wasted electrical energy from microhydro Gunung Sawur 1 and investigate its economic feasibility. This research begun with a survey of potency of wasted electrical energy in microhydro Gunung Sawur 1. The potency of waste electrical energy as the basic to calculate the production capacity of water distillation column. Feasibility study was carried out by using $N P V$ and $B / C$ ratio. The result showed that the potency of wasted electrical energy in microhydro of Gunung Sawur 1 up to $66 \mathrm{kwh} /$ day. The capacity of maximum power of planned distillation column was equal to the maximum power of microhydro dummy load. The production capacity of pure water was about 66 liters a day. The production of water purifier was feasible to do based on NPV value of IDR 30,121,094 and the B/C ratio value of 1.51 .
\end{abstract}

Keywords: distillation, microhydro, wasted energy

\section{PENDAHULUAN}

Pemurnian air merupakan proses pemisahan air murni dari komponenkomponen yang terlarut pada air tersebut seperti garam dan mineral. Pemurnian air menghasilkan air murni tanpa zat lain didalamnya (Malone dan Dolter, 2010).Air murni diperlukan untuk berbagai keperluan seperti pada industri, kegiatan laboratorium, keperluan medis, otomotif dan sebagainya. Harga air murni lebih mahal daripada harga air biasa (Rahmanto dan Febriani, 2017).

Salah satu proses pemurnian air yang banyak dilakukan adalah melalui proses destilasi termal. Proses ini memerlukan suatu unit destilasi yang terdiri dari evaporator dan kondensor. Air diuapkan di evaporator dengan bantuan energi panas, kemudian akan dikondensasikan dikondensor. Energi panas yang diperlukan pada proses pemurnian air dapat berasal dari energi listrik ataupun energi panas hasil pembakaran bahan bakar (Ibarz dan Canovas, 2003; Kucera, 2014; Smith 2011).

Pembangkit listrik tenaga mikrohidro (PLTMH) menghasilkan energi listrik untuk keperluan masyarakat maupun industri. PLTMH biasanya menggunakan pengendali beban elektronik (ELC) yang dilengkapi beban balast yang berupa elemen pemanas listrik untuk menstabilkan tegangan dan frekuensi listrik yang dihasilkan. Tegangan dan frekuensi listrik yang tidak stabil akan menyebabkan peralatan listrik konsumen PLTMH menjadi cepat rusak. ELC secara otomatis akan menyalurkan kelebihan daya listrik yang dihasilkan generator ke 
beban balast untuk menyeimbangkan beban apabila beban konsumen mengalami penurunan. ELC akan otomatis mengurangi suplai listrik ke beban balast apabila beban konsumen PLTMH meningkat, sehingga beban generator akan selalu stabil (Aung, 2015; IMIDAP, 2010; Kathirvel et al., 2015; Rahayuningtyas et $a l .$, 2012). Energi listrik yang disuplai ke beban balast selama ini terbuang begitu saja menjadi energi panas tanpa pemanfaatan (Rahmanto dan Femintasari. 2018). Berdasarkan potensi energi tersebut maka dapat direncanakan unit pemurni air destilasi dengan memanfaatkan sumber energi listrik terbuang di PLTMH Gunung Sawur 1 Lumajang. Hasil survei potensi energi listrik beban balast mikrohidro di PLTMH Gunung Sawur 1 diperlukan untuk perencanaan pemurnian air menggunakan destilator. Analisis ekonomi juga diperlukan untuk mengetahui kelayakan perencanaan tersebut.

\section{METODE PENELITIAN}

\section{Alat}

Alat-alat yang digunakan dalam penelitian ini adalah power logger Fluke 1735, kamera, alat tulis dan komputer.

\section{Tahapan Penelitian}

Survei Potensi Energi Listrik Beban Balast

Survei potensi energi listrik beban balast mikrohidro dilakukan di PLTMH Gunung Sawur 1 Lumajang. Potensi energi listrik beban balast diukur dengan menggunakan power logger Fluke. Clamp dan probe power loger terpasang selama 24 jam di beban balast mikrohidro (Gambar 1) untuk setiap kali sampling. Power logger hidup untuk merekam data kelistrikan. Pengunduhan data dilakukan setelah 3 hari perekaman data.

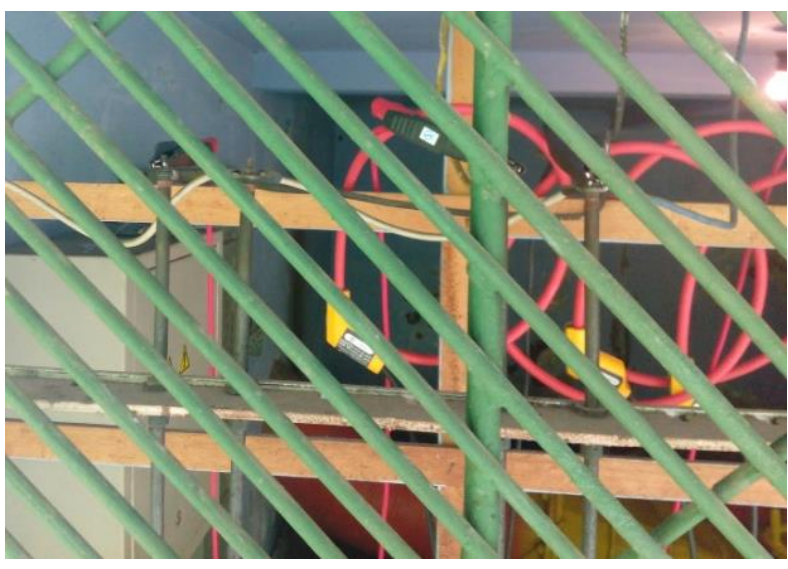

Gambar 1. Clamp dan probe power loger yang terpasang di Mikrohidro Gunung Sawur 1 Lumajang

Perhitungan Potensi Energi Beban Balast

Data hasil pengamatan potensi energi listrik beban balast PLTMH digunakan untuk menghitung potensi hariannya. Potensi energi tersebut digunakan untuk menghitung jumlah air yang dapat diuapkan. Perhitungan tersebut memperhatikan jumlah energi untuk menaikan suhu air dan energi untuk menguapkan air. Asumsi yang digunakan adalah air hanya akan menguap setelah mencapai titik didihnya.

\section{Metode Analisis}

Analisis kelayakan ekonomi perencanaan unit destilasi air tersebut dilakukan menggunakan NPV dan B/C ratio (Ardalan, 2000; Humpreys, 1991).

\section{HASIL DAN PEMBAHASAN}

\section{Potensi Energi Listrik Terbuang di PLTMH Gunung Sawur 1 Lumajang \\ Daya listrik beban balast PLTMH} Gunung Sawur 1 pada siang hari rata-rata adalah 3,69 kw. Daya listrik beban balast pada malam hari adalah sekitar $2,50 \mathrm{kw}$. Hasil pengamatan energi listrik yang terbuang melalui beban balast di PLTMH Gunung Sawur 1 disajikan pada Tabel 1. 
Tabel 1. Potensi energi beban balast di PLTMH Gunung Sawur 1 Lumajang

\begin{tabular}{ccc}
\hline Hari & $\begin{array}{c}\text { Daya }(\mathrm{kw}) \\
\text { rata-rata }\end{array}$ & Energi (kwh) \\
\hline 1 & 2,87 & 68,95 \\
2 & 3,24 & 66,44 \\
3 & 3,18 & 64,49 \\
4 & 3,05 & 59,10 \\
5 & 3,22 & 70,70 \\
6 & 3,19 & 69,66 \\
7 & 2,91 & 63,33 \\
\hline Rata-rata & 3,10 & 66,10 \\
\hline
\end{tabular}

Tabel 1 menunjukkan bahwa ratarata setiap hari ada sekitar 66,10 kwh energi yang terbuang melalui beban balast di PLTMH Gunung Sawur 1. Energi tersebut apabila dinilai dengan harga listrik PLN non-subsidi saat ini Rp 1.467,28/kwh adalah sebesar Rp 96.987,21 per hari atau lebih dari Rp 30 juta per tahun. Nilai energi tersebut apabila digunakan untuk memanaskan dan menguapkan air secara perhitungan akan mampu menguapkan sekitar 92 liter air.

\section{Komponen Destilator Pemurnian Air}

Destilator pemurni air terdiri dari beberapa komponen seperti yang terdapat pada Tabel 2. Komponen evaporator, kondensor dan elemen pemanas terbuat dari bahan stainless steel. Evaporator berfungsi untuk menguapkan air, sedangkan kondensor berfungsi untuk mengembunkan air yang telah diuapkan tersebut.

Tabel 2. Komponen utama destilator pemurni air menggunakan energi listrik terbuang PLTMH Gunung Sawur 1 Lumajang

\begin{tabular}{clc}
\hline No. & Komponen & Kebutuhan \\
\hline 1. & Evaporator & 2 buah \\
2. & Kondensor & 2 buah \\
3. & Elemen Pemanas & 2 pasang \\
4. & Handle & 2 buah \\
5. & Selang Air & 1 rol \\
6. & Jerigen & 20 buah \\
7. & Filter air & 1 unit \\
\hline
\end{tabular}

\begin{tabular}{clc}
\hline 8. & Dudukan & 1 buah \\
\hline
\end{tabular}

\section{Sumber Energi PanasDestilator}

Energi panas destilator pemurni air direncanakan berasal dari energi listrik beban balast PLTMH Gunung Sawur 1. Pengambilan energi listrik untuk evaporator pada sistem destilasi yang dirancang dilakukan dengan cara memindahkan koneksi listrik yang seharusnya menuju beban balast dialihkan ke elemen pemanas destilator. Pengalihan koneksi listrik tersebut dilakukan dengan menggunakan dua buah handle 3 fasa. Diagram kabel pengalihan koneksi listrik tersebut ditunjukkan pada Gambar 2.

Berdasarkan Gambar 2 koneksi listrik yang seharusnya menuju ke fasa 1 beban balast ke 1 dialihkan ke fasa 1 elemen pemanas ke 1 pada alat destilator. Koneksi listrik yang seharusnya menuju ke fasa 2 beban balast ke 1 dialihkan ke fasa 2 elemen pemanas ke 1 destilator. Koneksi listrik yang seharusnya menuju ke fasa 3 beban balast ke 1 dialihkan ke fasa 1 elemen pemanas ke 1 destilator. Hal itu juga berlaku untuk beban balast ke dua dan elemen pemanas destilator ke 2 . Pengalihan energi listrik beban balast dapat dilakukan semuanya ataupun sebagian saja dengan menggunakan handle yang ada.

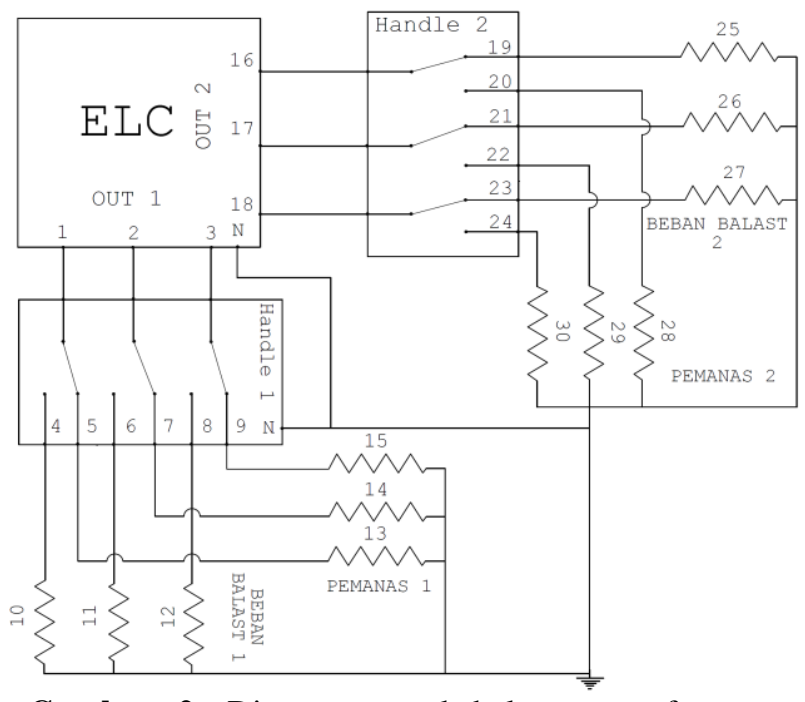

Gambar 2. Diagram pengkabelan pemanfaatan energi listrik beban balast 


\section{Elemen Pemanas Destilator}

Elemen pemanas destilator yang dirancang menggunakan dua buah rangkaian elemen pemanas listrik tiga fasa. Elemen pemanas tiga fasa dapat diperoleh dengan menggabungkan tiga buah elemen pemanas satu fasa menggunakan hubungan bintang ataupun hubungan delta. Hubungan kelistrikan yang digunakan pada elemen pemanas destilator disamakan dengan hubungan kelistrikan pada beban balast.

Nilai kapasitas daya elemen pemanas yang akan dipilih disamakan dengan yang digunakan pada beban balast. Penyamaan kapasitas elemen pemanas tersebut agar sistem kelistrikan PLTMH tetap terjaga keamananya.

\section{Komponen Biaya Destilator Pemurni Air}

Komponen biaya unit destilator air menggunakan energi listrik terbuang PLTMH Gunung Sawur 1 meliputi biaya investasi, biaya operator dan biaya perawatan. Biaya investasi peralatan destilator ditampilkan pada Tabel 3.

Destilator diasumsikan bekerja 6 hari dalam sepekan karena PLTMH Gunung Sawur 1 mengalami off untuk perawatan setiap hari Ahad jam 9:00 sampai 15:00 WIB. Biaya operator sekitar Rp 25.000,per hari sehingga dalam setahun mencapai Rp 7.800.000,-. Perawatan destilator dilakukan rata-rata setiap pekan dengan biaya sekitar Rp 50.000,-, sehingga dalam setahun mencapai Rp 2.600.000,-.
Tabel 3. Biaya investasi komponen utama destilator

\begin{tabular}{clr}
\hline No. & Komponen & \multicolumn{1}{c}{ Biaya (Rp) } \\
\hline 1. & 2 Evaporator & $4.000 .000,-$ \\
2. & 2 Kondensor & $8.600 .000,-$ \\
3. & 6 Elemen Pemanas & $2.400 .000,-$ \\
4. & 2 Handle & $500.000,-$ \\
5. & Selang Air & $300.000,-$ \\
6. & Jerigen & $800.000,-$ \\
7. & Unit filter air & $2.500 .000,-$ \\
8. & Dudukan & $1.000 .000,-$ \\
9. & Instalasi & $1.500 .000,-$ \\
\hline Jumlah & & $21.600 .000,-$ \\
\hline
\end{tabular}

\section{Kapasitas Produksi Destilator Pemurni} Air

Kapasitas produksi destilator pemurni air yang direncanakan dihitung berdasarkan potensi energi listrik terbuang di PLTMH Gunung Sawur 1. Destilator yang ada di pasaran misalnya GFL2012 mampu menghasilkan 4/3 liter air setiap kwh listrik yang digunakan. Kebutuhan air pendingin untuk kondensornya sekitar $58,38 \mathrm{~g} /$ detik atau setara dengan 210 $\mathrm{kg} / \mathrm{jam}$ (Rahmanto dan Febriani, 2017). Berdasarkan potensi energi listrik terbuang di PLTMH Gunung Sawur 1 maka secara perhitungan destilator akan mampu menghasilkan sekitar 88 liter air murni per hari. Akan tetapi karena energi listrik beban balast berfluktuasi maka diasumsikan setiap kwh listrik hanya mampu menghasilkan 1 liter air, sehingga kapasitas produksi destilator direncanakan akan menghasilkan sekitar 66,1 liter air per hari.

Berdasarkan kapasitas produksi air murni tersebut maka setiap hari akan menghasilkan pemasukan sebesar $\mathrm{Rp}$ 79.320,- atau Rp 24.747.840,- per tahun dengan asumsi harga jual air murni sebesar Rp 1.200,- per liter. Hasil analisis biaya beserta analisis NPV dan B/C ratio dengan asumsi suku bunga $12 \%$ dan umur ekonomi destilator 5 tahun ditunjukkan pada Tabel 4. 
Tabel 4. Analisis investasi destilator air

\begin{tabular}{ccc}
\hline No. & Biaya & Jumlah \\
\hline 1. & Pendapatan & Rp 61.520.251,- \\
2. & Biaya & Rp 27.394.438,- \\
3. & NPV & Rp 30.121.094,- \\
4. & B/C Ratio & 1,51 \\
\hline
\end{tabular}

NPV produksi air murni dengan memanfaatkan sumber energi listrik terbuang di PLTMH Gunung Sawur 1 Lumajang bernilai positif sehingga rencana kegiatan tersebut tergolong layak apabila dilaksanakan (Tabel 4). Nilai B/C ratio adalah 1,51 yang berarti lebih dari 1 yang mengindikasikan kegiatan tersebut layak untuk dijalankan.

\section{KESIMPULAN}

Rencana kapasitas produksi air murni dari pemanfaatan energi listrik terbuang PLTMH Gunung Sawur 1 adalah 66,1 liter per hari. Kegiatan tersebut layak bila akan dilaksanakan dengan nilai NPV sebesar Rp 30.121.094,- dan B/C ratio sebesar 1,51

\section{UCAPAN TERIMA KASIH}

Ucapan terima kasih ditujukan kepada Kemristekdikti yang telah mendukung terlaksananya penelitian ini melalui program Penelitian Dosen Pemula sumber dana DRPM Tahun Anggaran 2018. Penulis juga mengucapkan terimakasih kepada Bapak Sucipto selaku perintis dan pengelola PLTMH Gunung Sawur 1, Lumajang.

\section{DAFTAR PUSTAKA}

Ardalan, A. 2000. Economic \& Financial Analysis for Engineering and Project Management. Technomic Publishing Company, Pennsylvania.
Aung, N.W., Aung, Ze Ya. 2015. Design of electonic load controller by using combination methods for micro-hydro power plant and its control and monitoring program simulation. International Journal of Electrical, Electronics and Data Comunication, 3 (6).

Balke, E.C., William, L., Healy, and Tania Ullah. 2016. An assessment of efficient water heating option for an all-electric single family residence in a mixedhumid climate. Energy and Building, 133: 371-380.

Humphreys, K.K. 1991. Jelen's Cost and Optimization Engineering. MCGrawHill, New York

Ibarz, A., andCanovas,G.V.B. 2003. Unit Operation in Food Engineering. CRC Press, Boca Raton

IMIDAP. 2010. Modul Pelatihan Studi Kelayakan Mikrohidro. Dirjen Listrik dan Pemanfaatan Energi Departemen ESDM, Jakarta.

Kathirvel, C., Porkumaran, K., and Jaganathan, S. 2015. Design and implementation of improved electronic load controller for self-excites induction generator for rural electrification. The Scientific World Journal, Volume 2015.

Kucera J. 2014. Desalination Water from Water. Scrivener Publishing, Beverly.

Malone, L.J., and Dolter,T. 2010. Basic Concept of Chemistry. John Wiley \& Sons, New Jersey.

Rahayuningtyas, A., Santoso, T., dan Furqon, M. 2012. Sistem pengatur beban pada mikrohidro sebagai energi listrik pedesaan. Prosiding SnaPP, 3 (1).

Rahmanto, D.E., and V. Femintasari. 2018. An investigation of dummy load energy in Gunung Sawur 1 microhyro powerplant - Lumajang East Java. IOP Conference Series: Earth and Environment Science, 207. 
Rahmanto D.E, dan Febriani, S.D.A. 2017. Pendingin refrigerasi untuk air pendingin kondensor sebagai upaya penghematan penggunaan air. Prosiding Seminar Hasil Penelitian 2017. Politeknik Negeri Jember.

Smith P.G. 2011. Introduction to Food Process Engineering. Springer, New York.

Sujatno. 2011. Analisis sistem kendali beban elektronik sebagai stabilisasi energi listrik berbasis mikrokontroler. Seminar Nasional VIII SDM Teknologi Nuklir, Yogyakarta. 